\title{
Long-acting calcium channel blocker benidipine suppresses expression of angiogenic growth factors and prevents cardiac remodelling in a Type II diabetic rat model
}

\author{
S. Jesmin ${ }^{1}$, I. Sakuma ${ }^{1}$, Y.Hattori ${ }^{2}$, S. Fujiii ${ }^{1}$, A. Kitabatake ${ }^{1}$ \\ ${ }^{1}$ Department of Cardiovascular Medicine, Hokkaido University Graduate School of Medicine, Sapporo, Japan \\ ${ }^{2}$ Department of Pharmacology, Hokkaido University Graduate School of Medicine, Sapporo, Japan
}

\begin{abstract}
Aims/hypothesis. Calcium channel blockers, widely used for the treatment of hypertension and angina, could prevent cardiovascular complications in patients with diabetes. They can improve cardiac remodelling in animal models of a variety of cardiovascular diseases. Here, we examined the therapeutic effect of benidipine, a long-acting calcium channel blocker, on cardiac remodelling in Otsuka-Long-Evans-Tokushima-Fatty (OLETF) rats, a Type II (non-insulin-dependent) diabetes mellitus model.

Methods. The methods for morphometric analysis included double staining for coronary capillaries, dyebinding staining for collagen content and Masson's trichrome staining for perivascular fibrosis. Immunohistochemical and in situ hybridization techniques were used for detecting protein and mRNA expressions for vascular endothelial growth factors (VEGF), basic fibroblast growth factors (bFGF) and TGF- $\beta_{1}$, endothelial nitric oxide synthase (eNOS), and anti- and pro-apoptotic markers.

Results. OLETF rats showed an increased coronary capillary density, a reduced venular capillary propor-
\end{abstract}

tion, an increased cardiac collagen content and prominent cardiac perivascular fibrosis. In OLETF rat hearts, significant increases in vascular expressions for VEGF, bFGF and TGF- $\beta_{1}$ were found. Furthermore, the apoptosis signalling pathways, involving eNOS and apoptotic markers, were markedly altered, and coronary endothelial cell apoptosis was lower. These alterations with the exception of eNOS expression were significantly blocked by benidipine treatment.

Conclusion/interpretation. The suppressive effect of benidipine on overproduction of angiogenic growth factors could prevent cardiac angiogenesis and fibrosis, resulting in an improvement of cardiac remodelling in diabetes. As VEGF and bFGF potently block endothelial cell apoptosis execution, physiological apoptosis revived by benidipine treatment could also contribute to coronary vessel regression. [Diabetologia (2002) 45: 402-415]

Keywords Type II diabetes mellitus, calcium channel blocker, coronary capillary network, cardiac remodelling, angiogenic growth factors, coronary endothelial cell apoptosis, Otsuka-Long-Evans-TokushimaFatty rat.
Corresponding author: I. Sakuma, Department of Cardiovascular Medicine, Hokkaido University Graduate School of Medicine, N-15, W-7, Kita-ku, Sapporo 060-8638, Japan, e-mail: sakuichi@seagreen.ocn.ne.jp

Abbreviations: OLETF, Otsuka Long-Evans Tokushima Fatty; VEGF, vascular endothelial growth factor; bFGF, basic fibroblast growth factor; eNOS, endothelial nitric oxide synthase; ABCD, Appropriate Blood Pressure Control in Diabetes; KDR, fetal liver kinase 1; LV, left ventricular; LETO, LongEvans Tokushima Otsuka; OCT, optimum cutting temperature; TUNEL, terminal deoxynucleotidyl transferase-mediated dUTP nick end labelling; NO, nitric oxide; pBad phosphorylated Bad
Cardiovascular deterioration is one of the complicating features of diabetes mellitus. Patients suffering from diabetes mellitus are prone to disorders of the cardiovascular system, including microangiopathies and macroangiopathies, atherosclerosis, congestive heart failure and hypertension [1]. Mortality from cardiovascular disease is almost three times higher in diabetic patients than in the general population [2]. Several causes have been put forward to explain the development of cardiovascular dysfunction during diabetes. They include microangiopathic changes [3], abnormalities in vascular sensitivity and reactivity to 
vasoactive agents [4], altered autonomic function [5], increased stiffness of the ventricular wall associated with perivascular fibrosis [6] and changes in subcellular organelles which control ion movements, specifically intracellular calcium [7]. The Appropriate Blood Pressure Control in Diabetes (ABCD) trial has provided valuable evidence for the excellent efficacy of nisoldipine, a calcium channel blocker, as a first-line antihypertensive agent in preventing or delaying the progression of diabetic nephropathy, retinopathy, neuropathy and cardiovascular disease with Type II (non-insulin-dependent) diabetes mellitus [8]. This clinical trial stresses the importance of intensive blood pressure control for reducing the risk of cardiovascular events in hypertensive patients with Type II diabetes. However, the observation that a significantly greater benefit can be achieved with a calcium channel blocker in hypertensive patients with diabetes than in the subjects without diabetes [9] suggests that medication with calcium channel blockers could beneficially affect one or more unknown mechanisms in diabetes.

Several kinds of angiogenic growth factors are involved in the pathogenesis of diabetic complications. Vascular endothelial growth factor (VEGF) is known to be involved in the intraocular neovascularization caused by retinal ischaemia, including diabetic retinopathy [10]. The action of VEGF as an inducer of neovascularization is mediated by fetal liver kinase 1 (Flk-1, KDR) [11, 12]. High concentrations of VEGF and its receptor have been documented in the intraocular fluid in patients with proliferative diabetic retinopathy [10] and in animal models of ophthalmogic diseases involving retinal neovascularization $[13,14]$. Experimental and clinical studies suggest that VEGF plays a role in the development and progression of diabetic nephropathy $[15,16]$. The TGF- $\beta_{1}$ not only stimulates angiogenesis, possibly by upregulating expression of VEGF [17], but also promotes collagen synthesis $[18,19]$. It is highly expressed with fibrosis-related gene overexpression in the heart and kidney in a rat model of diabetes mellitus [15, 20]. Basic fibroblast growth factor (bFGF) could also participate in the pathological features of diabetic complications. There is a clinical report indicating a higher plasma concentration of bFGF in diabetic patients [21].

Cardiac remodelling is now recognized as an important aspect of cardiovascular disease progression and encompasses many changes with progressive heart failure [22]. Clinical indices of cardiac function in diabetes show increased left ventricular (LV) mass and wall thickness, reduced LV systolic function and increased arterial stiffness [23-25], suggesting the occurrence of cardiac remodelling during the development of diabetes. VEGF, TGF- $\beta_{1}$ and bFGF, associated with stimulation of angiogenesis and collagen synthesis, could be one of the crucial factors for the occurrence of cardiac remodelling during diabetes. Al- terations in coronary microvasculature produced by these growth factors could contribute to cardiac remodelling. Calcium channel blockers are theoretically effective in preventing cardiac remodelling because of their coronary vasodilating and anti-ischaemic properties. Indeed, calcium channel blockers such as amlodipine have been shown to improve cardiac remodelling in spontaneously hypertensive rats [26], myocardial infarcted rats [27] and idiopathic dilated cardiomyopathic hamsters [28]. In the light of the clinical studies showing the efficacy of calcium channel blocker therapy in preventing cardiovascular disease in patients with diabetes [8,9], the favourable actions of treatment with calcium channel blockers on cardiovascular functions in diabetes might be partly based on their beneficial effects on the remodelling process associated with growth factors causing cardiac angiogenesis and fibrosis. However, it is not clear what role is played by angiogenic growth factors in cardiac remodelling during diabetes. Furthermore, whether calcium channel blockers can favourably affect cardiac remodelling in diabetes and, if so, what the key is to these benefits, is not clear.

In this study, we examined the therapeutic effect of benidipine, a long-acting calcium channel blocker, on cardiac remodelling in Otsuka Long-Evans Tokushima Fatty (OLETF) rats. This strain manifests stable clinical and pathological features that resemble human Type II diabetes mellitus [29]. Briefly, OLETF rats are characterized by late onset of hyperglycaemia, and a mild and chronic course of diabetes, as well as mild obesity, an inheritance by males, and also renal and cardiac complications. We investigated possible contribution of VEGF, TGF- $\beta_{1}$ and bFGF to the development of cardiac remodelling in OLETF rats with and without benidipine treatment. It is believed that growth factors such as VEGF not only stimulate angiogenesis, which is mediated by proliferation, migration and remodelling of endothelial cells from pre-existing vessels, but simultaneously inhibit endothelial cell apoptosis [30]. The inhibitory effect of VEGF on endothelial cell apoptosis is due to its actions on endothelial nitric oxide synthase (eNOS) and pro-apoptotic or anti-apoptotic proteins [30]. Thus, endothelial cell apoptosis and changes in the apoptosis signalling pathways were also evaluated in coronary vessels from diabetic rats.

\section{Materials and methods}

Experimental animals. The experimental design was approved by the Hokkaido University School of Medicine Animal Care and Use Committee. Male OLETF rats, a model of Type II diabetes mellitus established in 1992 [29], were obtained from Tokushima Research Institute, Otsuka Pharmaceutical (Tokushima, Japan). OLETF rats show a prediabetic phase characterized by postprandial hyperglycaemia and insulin-resistance at 15 weeks of age, a Type-II-diabetic phase showing impaired 
glucose tolerance with hyperglycaemia after 18 weeks of age, and a Type-I-diabetic phase after 40 weeks of age [20, 29]. Male Long-Evans Tokushima Otsuka (LETO) rats, which were developed from the same colony by selective mating but did not develop diabetes, served as normal control subjects. We prepared three groups of twelve animals each: a control group, diabetes group and benidipine-treatment diabetes group. In the benidipine-treatment group, benidipine was given daily to OLETF rats from 8 weeks of age at a peroral dose of $3 \mathrm{mg} / \mathrm{kg}$ in $0.3 \%$ carboxymethyl cellulose solution. Body weight, blood pressure, plasma glucose and plasma insulin of the animals were monitored periodically from the age of 8 to 20 weeks. Rats were killed at 20 weeks of age under ether anaesthesia, and the hearts were rapidly excised. After the heart and LV weights were measured, some portion of left ventricle was dipped into optimum cutting temperature (OCT) compound (Sakura Finetechnical, Tokyo, Japan) and immediately frozen in liquid nitrogen. The remaining portion was preserved at $-80^{\circ} \mathrm{C}$ without OCT compound or was fixed in $4 \%$ paraformaldehyde and then embedded in paraffin.

Morphometric analysis. Cross-sections $16-\mu$ m thick were taken at the widest part of left ventricle. Double staining of sections was carried out to differentiate arteriolar and venular capillaries $[31,32]$. Arteriolar capillaries were stained blue because they contained alkaline phosphatase, while venular capillaries were stained red because they contained dipeptidyl peptidase IV. Intermediate capillaries were stained violet as they contained both enzymes. Capillaries and myocytes were drawn using a projection tube attached to a microscope. The numbers of venular, intermediate and arteriolar capillaries were counted in a given microscopic field. Capillary density, myocyte number, capillary to myocyte ratio, capillary domain area and myocyte scan area were determined as previously described [33].

For Elastica-Mansson's trichrome staining, 8 - $\mu \mathrm{m}$-thick frozen cryostat sections were prepared. After acetone fixation, the sections were incubated overnight at $4{ }^{\circ} \mathrm{C}$ in reagent $\mathrm{D}$ containing saturated picric acid, mildform $10 \mathrm{~N} 10 \%$ formalin neutral buffer and acetic acid. Subsequently, the sections were incubated with haematoxylin for $5 \mathrm{~min}$, and then incubated for $3 \mathrm{~min}$ at room temperature in reagent $\mathrm{A}$ containing ponseau de xyline, fuschin acid and acetic acid. Finally, the sections were incubated for $15 \mathrm{~min}$ at room temperature in reagent $\mathrm{C}$ containing light green $\mathrm{SF}$ and acetic acid following incubation for $15 \mathrm{~s}$ in reagent $\mathrm{B}$ containing 12 tungsto-phosphoric acid $n$-hydrate and orange G. The transsectional images of coronary arterioles with inner diameter of less than $100 \mu \mathrm{m}$ were analysed using an image-analysing software (Microcomputer Imaging Device, Imaging Research, St. Catharine, Ontario, Canada). The wall-to-lumen ratio was calculated as the area of the vessel wall divided by the total area of vessel lumen. The area of perivascular fibrosis was estimated as the per cent fibrosis surrounding the blood vessel for each visual field area of the blood vessel.

Collagen in tissue samples was detected using a Collagen staining kit (Collagen Research Center, Tokyo, Japan). Then, the ratio of collagen to non-collagen protein was calculated according to the previous report [34].

DNA nick end labelling. Five- $\mu$ m-thick sections were deparaffinized with a graded series of xylene and ethanol solutions. Nuclei of tissue sections were stripped from proteins by incubation with proteinase $\mathrm{K}$ for $15 \mathrm{~min}$ at $37^{\circ} \mathrm{C}$. The sections were then immersed in cacodylate buffer for $10 \mathrm{~min}$ at room temperature. Non-specific binding was blocked with normal goat serum. The assay for in situ terminal deoxynucleotidyl transferase-mediated dUTP nick end labelling (TUNEL) was performed using Apop Tag Plus (Oncor Inc., Gaithersburg, Md., USA). Negative control slides were processed in the absence of terminal deoxynucleotidyl transferase. TUNEL-positive apoptotic cells were visualized by staining with avidin-biotin peroxidase complex, where the nuclei of TUNEL-positive cells stained brown. Then the slides were counterstained with methylene blue. Apoptotic endothelial cells were counted and expressed as a percentage of total number of endothelial cells in randomly selected vessels. Endothelial origin of the cells was confirmed by colocalization of TUNEL positivity with anti-von Willebrand factor antibody staining.

Immunohistochemistry. Immunohistochemical studies were done with the following commercially available antibodies: anti-human VEGF polyclonal antibody (Immunobiological Laboratories, Fujioka, Japan), anti-human Flk-1 polyclonal antibody (Santa Cruz Biotechnology, Santa Cruz, Calif., USA), anti-human TGF- $\beta_{1}$ polyclonal antibody (R and D Systems, Minneapolis, Minn., USA), anti-bFGF monoclonal antibody (Upstate Biotechnology, Lake Placid, N. Y., USA), antihuman Bcl-2 polyclonal antibody (Santa Cruz Biotechnology, Santa Cruz, Calif., USA), anti-mouse Bax polyclonal antibody (Santa Cruz Biotechnology) anti-human eNOS polyclonal antibody (Transduction Laboratories, San Diego, Calif., USA), anti-human/mouse caspase-3 active form ( $\mathrm{R}$ and S System) or anti-mouse phosphorylated Bad (p-Bad) (Santa Cruz Biotechnology). Eight- $\mu \mathrm{m}$-thick frozen cryostat sections were fixed in acetone for $10 \mathrm{~min}$ at $4{ }^{\circ} \mathrm{C}$ and air-dried. Endogenous peroxidase activity was quenched by incubation in $3 \%$ hydrogen peroxide for $15 \mathrm{~min}$. The sections were then blocked by normal goat serum to prevent non-specific staining by the secondary antibody. After incubation overnight at $4{ }^{\circ} \mathrm{C}$ with primary antibodies, the sections were exposed to the secondary goat antirabbit antibody, goat anti-mouse antibody or rabbit anti-goat antibody conjugated with horseradish peroxidase. Bound antibody was visualized by a light microscopy with diaminobenzidine. Omission of primary antibodies and staining with nonimmune $\mathrm{IgG}$ served as negative controls for each antibody in the present study. Quantitation of immunoreactivity by pixel intensity was analysed using an image-analysing software (Microcomputer Imaging Device).

Immunofluorescent staining. After overnight incubation with anti-human Bcl-2, anti-mouse Bax polyclonal anti-human and mouse caspase- 3 active form or anti-mouse pBad antibody, in the same way as mentioned above, the sections were exposed to the fluorescence secondary antibody, $\mathrm{Cy}^{\mathrm{TM}} 3$-conjugated AffiniPure donkey anti-rabbit IgG or fluorescein-conjugated AffiniPure goat anti-mouse IgG (Jackson Immuno Research Laboratories, Westgrove, Penn., USA), for $2 \mathrm{~h}$ according to the manufacturer's instructions. The samples processed without primary antibodies served as negative controls. Immunofluorescent images were obtained using Laser Scanning Confocal Imaging System (MRC-1024, Bio-Rad, Maryland, UK). The Bcl-2 to Bax ratio was determined quantitatively using the free software NIH image (Wayne Rasband, National Institute of Health, Bethesda, Md., USA).

In situ hybridization protocol. Twenty- $\mu$ m-thick tissue sections were prepared and mounted on glass slides precoated with 3amino-propyltriethoxysilane. The sections were then fixed by $4 \%$ paraformaldehyde for 10 min with $0.25 \%$ acetic anhydride in $0.1 \mathrm{~mol} / \mathrm{l}$ triethanolamine- $\mathrm{Hcl}(\mathrm{pH} 8.0)$. The hybridization procedure was done as previously described [35]. The probes were complementary to nucleotide residues 62 to 106 of VEGF cDNA (accession number AF 222779), 541 to 585 of KDR cDNA (accession number U 93306), 841 to 885 of 
Table 1. Body, heart and LV weights in LETO, OLETO and benidipine-treatment OLETF rats at 20 weeks of age

\begin{tabular}{lllll}
\hline Group & Body weight $(\mathrm{g})$ & Heart weight $(\mathrm{mg})$ & LV weight $(\mathrm{mg})$ & LVW/BW \\
\hline LETO & $424 \pm 17$ & $1039 \pm 89$ & $815 \pm 69$ & $1.9 \pm 0.1$ \\
OLETF & $550 \pm 38^{*}$ & $1448 \pm 111^{*}$ & $1139 \pm 82^{*}$ & $2.1 \pm 0.1^{*}$ \\
Benidipine & $541 \pm 31^{*}$ & $1371 \pm 68^{*}$ & $1088 \pm 54^{*}$ & $2.0 \pm 0.1$ \\
\hline
\end{tabular}

Data are means \pm SD of 12 animals; LVW/BW was calculated as the ratio of LV weight to body weight $\times 100$

$* p<0.05$ vs LETO

Table 2. Blood pressure, heart rate and plasma glucose and insulin levels in LETO, OLETF and benidipine-treatment OLETF rats

\begin{tabular}{|c|c|c|c|c|}
\hline Group & $\begin{array}{l}\text { Systolic pressure } \\
(\mathrm{mmHg})\end{array}$ & $\begin{array}{l}\text { Heart rate } \\
\text { (beats/min) }\end{array}$ & $\begin{array}{l}\text { Plasma glucose } \\
(\mathrm{mmol} / \mathrm{l})\end{array}$ & $\begin{array}{l}\text { Plasma insulin } \\
(\mathrm{pmol} / \mathrm{l})\end{array}$ \\
\hline $\begin{array}{l}8 \text { weeks } \\
\text { LETO } \\
\text { OLETF } \\
\text { Benidipine }\end{array}$ & $\begin{array}{l}121 \pm 6 \\
120 \pm 8 \\
122 \pm 7\end{array}$ & $\begin{array}{l}513 \pm 37 \\
469 \pm 27^{*} \\
461 \pm 27^{*}\end{array}$ & $\begin{array}{c}9.41 \pm 1.36 \\
11.06 \pm 0.66^{*} \\
12.21 \pm 1.97^{*}\end{array}$ & $\begin{array}{l}180 \pm 90 \\
253 \pm 71^{*} \\
285 \pm 55^{*}\end{array}$ \\
\hline $\begin{array}{l}12 \text { weeks } \\
\text { LETO } \\
\text { OLETF } \\
\text { Benidipine }\end{array}$ & $\begin{array}{l}120 \pm 8 \\
130 \pm 7 * \\
124 \pm 6\end{array}$ & $\begin{array}{l}465 \pm 29 \\
454 \pm 25 \\
481 \pm 28 * *\end{array}$ & $\begin{array}{c}9.72 \pm 1.14 \\
11.31 \pm 1.46^{*} \\
11.79 \pm 0.90^{*}\end{array}$ & $\begin{array}{l}341 \pm 98 \\
670 \pm 242 * \\
597 \pm 211 *\end{array}$ \\
\hline $\begin{array}{l}16 \text { weeks } \\
\text { LETO } \\
\text { OLETF } \\
\text { Benidipine }\end{array}$ & $\begin{array}{l}121 \pm 8 \\
134 \pm 14^{*} \\
119 \pm 11^{* *}\end{array}$ & $\begin{array}{l}440 \pm 66 \\
437 \pm 33 \\
483 \pm 29 *, * *\end{array}$ & $\begin{array}{l}10.23 \pm 1.15 \\
11.18 \pm 1.18^{*} \\
11.23 \pm 1.25^{*}\end{array}$ & $\begin{array}{l}320 \pm 100 \\
773 \pm 418^{*} \\
755 \pm 534^{*}\end{array}$ \\
\hline $\begin{array}{l}20 \text { weeks } \\
\text { LETO } \\
\text { OLETF } \\
\text { Benidipine }\end{array}$ & $\begin{array}{l}129 \pm 11 \\
140 \pm 11^{*} \\
132 \pm 14 * *\end{array}$ & $\begin{array}{l}429 \pm 44 \\
432 \pm 31 \\
460 \pm 29 *, * *\end{array}$ & $\begin{array}{c}9.12 \pm 0.72 \\
10.93 \pm 1.85^{*} \\
11.20 \pm 1.07^{*}\end{array}$ & $\begin{array}{l}401 \pm 113 \\
743 \pm 280^{*} \\
748 \pm 233^{*}\end{array}$ \\
\hline
\end{tabular}

TGF- $\beta_{1}$ cDNA (accession number AF 239170), 1 to 45 of FGF cDNA (accession number D 64085), 441 to 485 of Bcl-2 cDNA (accession number L 14680), 301 to 345 of Bax cDNA (accession number S 76511) and 841 to 885 of eNOS cDNA (accession number $X$ 76309). The oligonucleotides were labelled with ${ }^{35}$ S-dATP using terminal deoxyribonucleotidyl transferase. The radiolabelled probes were hybridized to the tissue in a prehybridisation buffer for $10 \mathrm{~h}$ at $42^{\circ} \mathrm{C}$. The sections were either exposed to Hyperfilm- $\beta$ max (Amersham, Bucks, UK) for 4 weeks or dipped in Kodak NTB2 nuclear track emulsion and exposed for 4-8 weeks. The specificity of in situ hybridization was confirmed by the disappearance of signals when excessive doses of the corresponding cold oligonucleotides were added to the hybridization fluid. The mRNA grains for each blood vessel were quantified using an image-analysing software (Microcomputer Imaging Device).

Statistical analysis. Values are shown as the means \pm SD. Data were analysed using the Stat View II program (Abacus Concepts, Berkeley, Calif., USA). Comparisons among groups were made by ANOVA with multiple comparisons by Fisher's protected least significance $t$ test or F-t test. A $p$ value of less than 0.05 was considered statistically significant.

\section{Results}

Characteristics of experimental animals. At 20 weeks of age, the body weight of OLETF rats was significantly greater than that of LETO rats (Table 1 ).
Benidipine treatment had no influence on weight gain. Heart and LV weights were 1.4-fold larger in OLETF than in LETO rats. As a result, the ratio of LV weight to body weight was significantly higher in OLETF than in LETO rats. Treatment of OLETF rats with benidipine did not alter the increases in heart and LV weights and LV weight corrected for body weight.

From 8 to 20 weeks of age, the fed plasma glucose and insulin levels were always higher in OLETF than in LETO rats regardless of whether benidipine was given or not (Table 2). Blood pressure of OLETF rats was slightly increased with aging and was higher $(p<0.05)$ than that of LETO rats throughout the age range of 12 to 20 weeks. Treatment of OLETF rats with benidipine lowered the blood pressure to the value of LETO rats at the same age. However, heart rate tended to be increased by benidipine treatment.

The results of the oral glucose tolerance test are shown in Table 3. The animals received a $50 \%$ glucose solution $(2 \mathrm{~g} / \mathrm{kg})$ after $16 \mathrm{~h}$ fasting. Blood samples were collected just before and 1 and $2 \mathrm{~h}$ after glucose loading. The oral glucose tolerance test indicated higher $(p<0.05)$ concentrations of plasma glucose and insulin in OLETF than in LETO rats. Treatment with benidipine did not significantly alter the impairment of glucose tolerance seen in OLETF rats. 


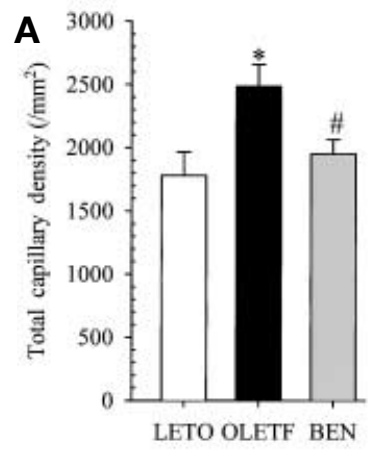

Fig. 1 (A, B). Total capillary density, the number of venular, intermediate and arteriolar capillaries $(\mathbf{A})$, and proportions of venular (VC), intermediate (IC) and arteriolar (AC) capillaries (B), obtained by the double staining method, in the crosssections of LV subendocardium from LETO (empty bars), OLETF (solid bars) and benidipine-treatment OLETF (BEN, shaded bars) rats. The total capillary density is expressed as the number per $\mathrm{mm}^{2}$ and the capillary proportions are as $\%$ of total capillaries. Data are shown as the means \pm SD (30 fields $\times 12$ samples). ${ }^{*} p<0.01$ vs LETO; ${ }^{*} p<0.01$ vs OLETF

Morphometric changes. The morphometric analysis by the double staining method showed an increase $(p<0.01)$ in the total capillary density in LV tissues of OLETF rats compared with that of LETO rats (Fig.1A). On the other hand, the ratio of venular to total capillaries was much less in OLETF than in LETO rats, and the intermediate and arteriolar capillary portions were markedly increased in OLETF rats (Fig. 1B). Treatment of OLETF rats with benidipine reversed the increased total capillary density (Fig.1A). Furthermore, benidipine treatment increased $(p<0.01)$ the proportion of venular capillaries and decreased $(p<0.01$ arteriolar and intermediate proportions, resulting in a trend toward normalization of the capillary network (Fig.1B).

The ratio of capillary to myocyte, which was defined as the number of capillaries assigned to one myocyte, was higher $(p<0.01)$ in OLETF than in LETO rats (Fig. 2A). In addition, the capillary domain area, which shows an area supplied by a single capillary and was defined as the area where one capillary provides oxygen, was decreased $(p<0.01)$ in OLETF rats (Fig. 2B). Treatment of OLETF rats with benidipine returned the capillary to myocyte ratio and the capillary domain area to the values obtained in LETO rats (Fig.2A and B). Myocyte scan area showed modest cardiomyocyte hypertrophy in OLETF rats, which was restored by benidipine treatment (Fig. 2C).

Figure 3 shows representative photomicrographs of Masson's trichrome-stained LV sections from LETO, OLETF and benidipine-treatment OLETF rats. The wall-to-lumen ratio of coronary arterioles in OLETF rats $(2.89 \pm 0.60, n=12, p<0.01)$ was about threefold greater than that in LETO rats $(1.01 \pm 0.18, n=12)$. Benidipine treatment reduced the ratio $(1.27 \pm 0.22, n=12, p<0.01)$. The area of perivascular fibrosis in coronary arterioles, which was corrected for the total vessel area, was larger in OLETF than in LETO rats $(87 \pm 15 \%$ vs. $26 \pm 2 \%$, $p<0.01)$. The development of fibrosis in the perivascular area in OLETF rats was prevented by benidipine treatment $(30 \pm 5 \%, p<0.01)$. Furthermore, the ratio of collagen to non-collagen protein in LV tissues of OLETF rats $(7.1 \pm 1.2 \%, n=12)$ was higher $(p<0.01)$ than that of LETO rats $(4.8 \pm 0.2 \%$, $n=12)$, and this change was completely blocked by benidipine treatment $(5.0 \pm 0.3 \%, n=12)$.

Protein and $m R N A$ expressions of angiogenic growth factors. VEGF and its receptor KDR were very weakly stained in the LV cross-sections from LETO rats (Fig. 4A and B). In contrast, OLETF rats showed diffuse and marked immunoreactivity for these molecules (Fig. 4A and B). Positive staining for VEGF and KDR was mainly in coronary vessels, while being weak and null in cardiomyocytes, respectively. The bFGF protein expression in coronary vessels was moderately detected in LETO rats, whereas this protein was more abundantly expressed in OLETF rats

Table 3. Oral glucose tolerance test in LETO, OLETF and benidipine-treatment OLETF rats at 20 weeks of age

\begin{tabular}{|c|c|c|c|c|c|c|}
\hline & \multicolumn{3}{|c|}{ Plasma glucose $(\mathrm{mmol} / \mathrm{l})$} & \multicolumn{3}{|c|}{ Plasma insulin (pmol/l) } \\
\hline & 0 & $1 \mathrm{~h}$ & $2 \mathrm{~h}$ & 0 & $1 \mathrm{~h}$ & $2 \mathrm{~h}$ \\
\hline LETO & $7.4 \pm 0.8$ & $10.7 \pm 1.1$ & $7.6 \pm 1.0$ & $125 \pm 55$ & $419 \pm 166$ & $202 \pm 59$ \\
\hline OLETF & $8.3 \pm 0.7 *$ & $19.1 \pm 4.4^{*}$ & $11.6 \pm 3.8^{*}$ & $202 \pm 80 *$ & $696 \pm 208^{*}$ & $430 \pm 152^{*}$ \\
\hline Benidipine & $8.4 \pm 0.5^{*}$ & $17.9 \pm 3.3^{*}$ & $9.4 \pm 1.3^{*}$ & $220 \pm 80^{*}$ & $760 \pm 289 *$ & $567 \pm 269 *$ \\
\hline
\end{tabular}

Data are means \pm SD of 12 animals

$* p<0.05$ vs LETO 

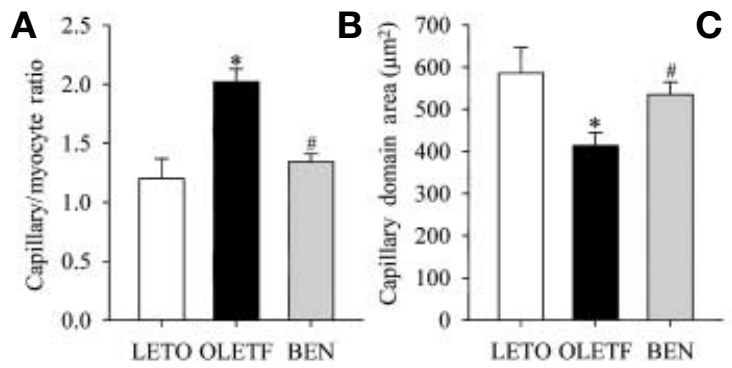

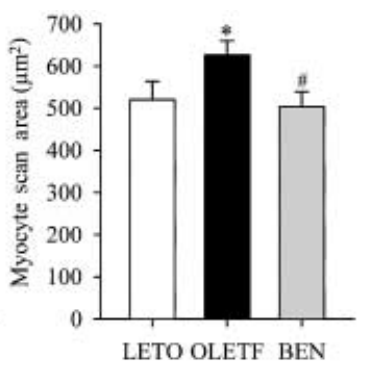

Fig. 2 (A-C). Ratio of capillary to myocyte (A), capillary domain area $(\mathbf{B})$ and myocyte scan area $(\mathbf{C})$ in the LV cross-sections from LETO, OLETF and benidipine-treatment OLETF $(\mathrm{BEN})$ rats. Data are shown as the means \pm SD $(30$ fields $\times 12$ samples). ${ }^{*} p<0.01$ vs LETO; ${ }^{*} p<0.01$ vs OLETF

(Fig.4C). Although TGF- $\beta_{1}$ was not detectable in normal coronary vessels, its expression in diabetic coronary vessels was markedly increased (Fig. 4D). Benidipine treatment dramatically reduced the expressions of VEGF, KDR, bFGF and TGF- $\beta_{1}$ proteins in coronary vessels seen in OLETF rats (Fig. 4).

VEGF, KDR, bFGF and TGF- $\beta_{1}$ mRNAs were evidently increased in the LV cross-sections from OLETF rats compared with the findings in those from LETO rats (Fig.5). The expressions of their mRNAs were abundant in both coronary vessels and cardiomyocytes of OLETF rats. When the numbers of mRNA grains for each coronary vessel were calculated, VEGF, KDR, bFGF and TGF- $\beta_{1}$ mRNAs in OLETF rats were increased 2.9-fold, threefold, 2.4fold and 2.9-fold compared with LETO rats (Fig. 6). Treatment with benidipine significantly reduced the expressions of their mRNAs nearly to those of nondiabetic controls (Figs. 5 and 6).

Fig.3 (A-C). Photomicrographs of Masson's trichromestained LV sections from LETO (A), OLETF (B) and benidipine-treatment OLETF (C) rats. Masson's trichrome stains (arrow) show more prominent perivascular fibrosis in OLETF than in LETO and benidipine-treatment OLETF rats. Magnification $\times 400$
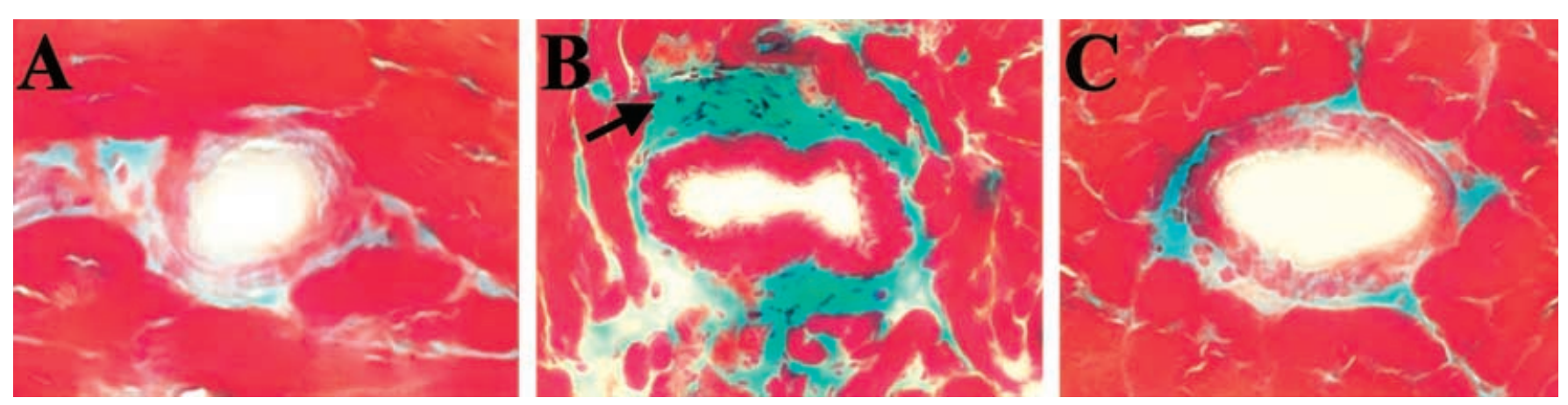

Expressions of protein and $m R N A$ for eNOS. Immunohistochemical studies showed more abundant eNOS protein expression in the LV cross-sections from OLETF than in those from LETO rats (Fig. 7). The location of positive staining for eNOS was largely within coronary vessels, especially the intimal surface. The increase in positive staining for eNOS protein in coronary vessels of OLETF rats correlated with an increase in eNOS mRNA which was obtained from in situ hybridization experiments (Fig. 8). The results of quantitative analysis showed a 1.9-fold increase in eNOS mRNA expression in OLETF compared with LETO rats $(p<0.01)$. In OLETF rats treated with benidipine, expressions of eNOS protein and mRNA were more pronounced (Figs. 7 and 8).

Protein and $m R N A$ expressions of Bcl-2 and Bax. Increased immunofluorescent staining for $\mathrm{Bcl}-2$, an anti-apoptotic marker, was detected in the LV crosssections of OLETF compared with those of LETO rats (Fig. 9A). In contrast, LETO rats showed stronger staining for Bax, a pro-apoptotic marker, than OLETF rats (Fig. 9B). Both Bcl-2 and Bax were observed mainly in coronary vessels. Treatment of OLETF rats with benidipine reduced Bcl-2 expression and enhanced Bax expression as seen in LETO rats (Fig.9A and B). The same results were obtained in immunohistochemical studies (data not shown). The Bcl-2-to-Bax ratio was higher in OLETF $(3.5 \pm 0.8, n=12, p<0.01)$ than in LETO rats $(0.5 \pm 0.1, n=12)$, and benidipine treatment reversed the ratio in OLETF rats $(0.6 \pm 0.1, n=12, p<0.01)$.

In situ hybridization studies showed that Bcl2 mRNA was increased and Bax mRNA was decreased in OLETF compared with LETO rats (Fig.10). When the numbers of mRNA grains for 


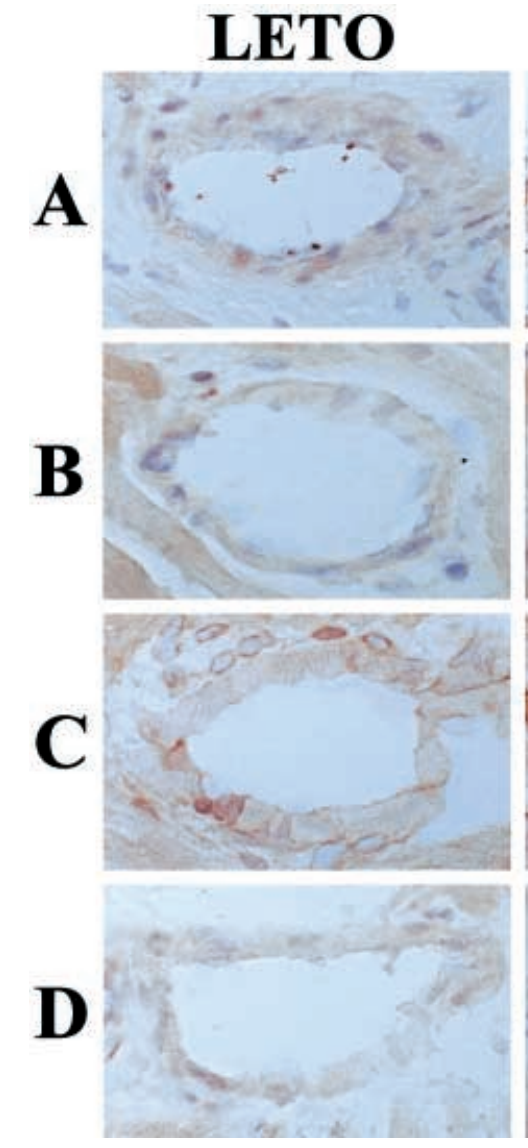

LETO
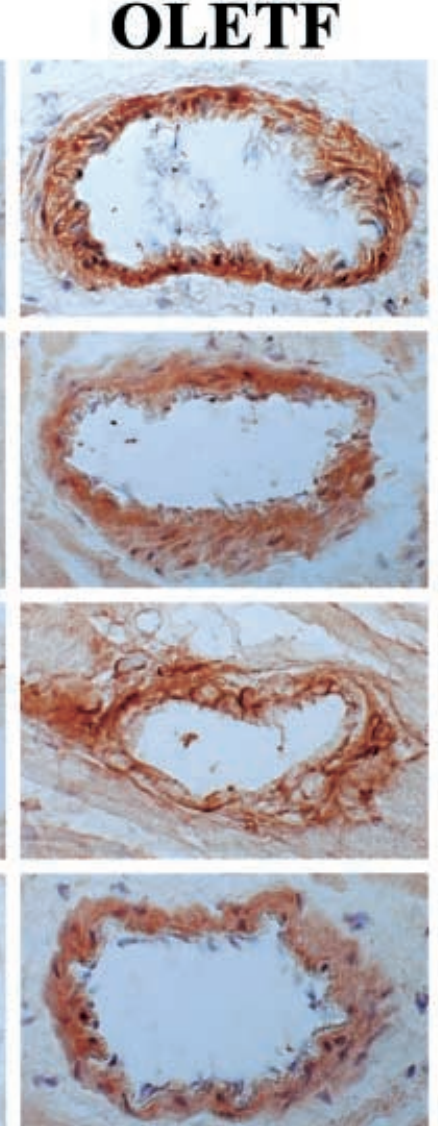

BEN
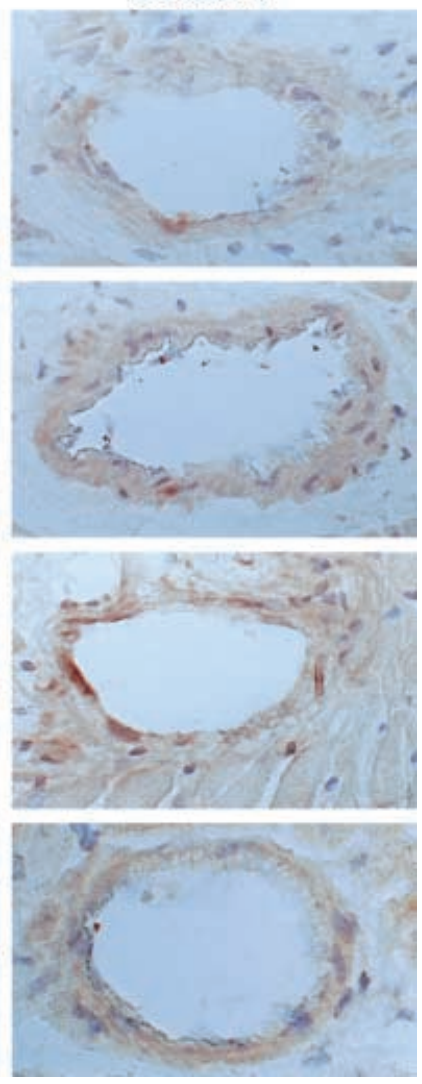

Fig. 4 (A-D). Immunohistochemical findings for VEGF (A), $\operatorname{KDR}(\mathbf{B})$, bFGF $(\mathbf{C})$ and TGF- $\beta_{1}$ (D) proteins in the LV cross-sections from LETO (left panels), OLETF (middle panels) and benidipine-treatment OLETF (BEN) (right panels) rats. Immunostaining was mainly focused on coronary vessels. Magnification $\times 400$

each coronary vessel were calculated, the ratio of Bcl2 mRNA-to-Bax mRNA was $0.5 \pm 0.1 \quad(n=12)$ in LETO and $2.7 \pm 0.8(n=12, p<0.01)$ in OLETF rats. The increased ratio in OLETF rats was inhibited by benidipine treatment $(0.6 \pm 0.1, n=12, p<0.01)$.

Protein expressions of active caspase- 3 and pBad. Immunofluorescent staining for active caspase-3, a member of caspase superfamily which initiates apoptotic events, showed that its expression was diminished in coronary vessels of the LV cross-sections of OLETF compared with those of LETO rats (Fig.11A). On the other hand, expression of pBad, which acts as a downstream element in the anti-apoptotic signalling pathway, was more abundant in OLETF than in LETO rats (Fig. 11B). The changes in their expression levels seen in OLETF rats were reversed by benidipine treatment (Fig. 11).

Apoptosis of endothelial cells. To assess whether diabetes can modify apoptotic death of endothelial cells of coronary vessels, the tissues were labelled with an in situ TUNEL assay. As shown in Figure 12A, TUNEL-positive apoptotic endothelial cells in coronary vessels were threefold lower in OLETF than in LETO rats. Benidipine treatment returned the reduced number of apoptotic endothelial cells in OLETF rats to same level as LETO rats (Fig.12A). TUNEL-positive cells were detected not only in endothelium but also in smooth muscle (Fig. 12B). The origin of TUNEL-positive apoptotic endothelial cells were confirmed by the finding that the cells were also positive for von Willebrand factor.

\section{Discussion}

We found that OLETF rats had increases in total coronary capillary density, cardiomyocyte area, cardiac collagen deposition and perivascular fibrosis at 20 weeks of age. At this age, OLETF rats had an early manifestation of glucose metabolic disorders [20, 29, 36]. Consistently, significant insulin resistance and impaired glucose tolerance with hyperglycaemia were observed in this study. The increased total capillary density resulted from increases in intermediate and arteriolar capillaries. Indeed, the proportion of venular capillaries was markedly reduced in OLETF rats. Although capillary angiogenesis usually initiates from the venular site [37], the lower proportion of 

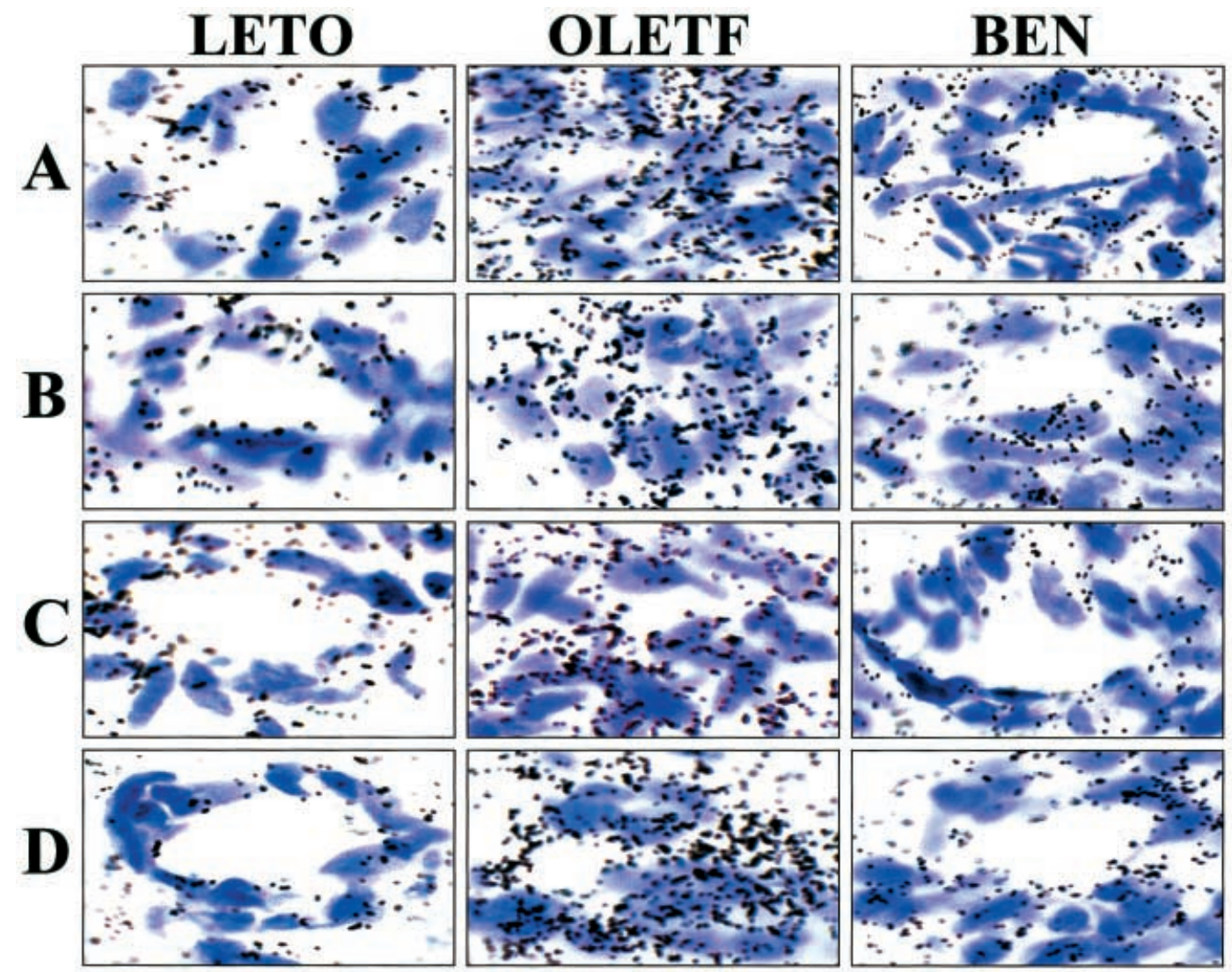

Fig.5. In situ hybridization analysis showing gene expressions for VEGF (A), KDR (B), bFGF (C) and TGF- $\beta_{1}(\mathbf{D})$ in the LV cross-sections from LETO (left panels), OLETF (middle panels) and benidipine-treatment OLETF (BEN) (right panels) rats. Nuclei in coronary vessels were stained with hematoxylin as bluish-violet. The presence of mRNA is shown by black grains in the field. Magnification $\times 400$

venular capillaries is in good agreement with the result obtained in streptozotocin-induced diabetic rats [38]. Furthermore, in diabetic retinopathy in human beings, neovascularization arises from the venous side [39], but morphometric evaluation of venular and arteriolar capillary density indicates an increased proportion of arteriolar capillaries [40]. The increased total capillary density resulted in an increase in the ratio of capillary to myocyte and a decrease in the capillary domain area, suggesting that oxygen diffusion distance was shortened as a compensatory change. Our study shows that VEGF, bFGF and TGF- $\beta_{1}$ were highly expressed in coronary vessels of the OLETF rat heart at both protein and mRNA levels. Protein and mRNA expression of KDR, which mediates most of the VEGF effects including angiogenesis [11, 12], was also markedly increased in OLETF rats. Because VEGF is known to play an essential role in angiogenesis [41], overexpression of VEGF and its receptor suggests that VEGF could participate in promoting the formation of new capil- laries from pre-existing coronary vessels in the OLETF rat heart. Both bFGF and TGF- $\beta_{1}$ are well known not only to induce angiogenesis but also to be powerful stimulators of cardiomyocyte hypertrophy [42] and collagen synthesis in the heart [43, 44]. Thus, the increases in protein and gene expressions of $\mathrm{bFGF}$ and TGF- $\beta_{1}$ could be responsible for perivascular fibrosis, interstitial collagen deposition and cardiomyocyte hypertrophy found in the OLETF rat heart. Therefore, it would be reasonable to conclude that profound structural changes in the heart, referred to as cardiac remodelling, seen in OLETF rats are causally related to overproduction of angiogenic growth factors and the associated receptor.

This study showed that treatment with benidipine, a long-acting calcium channel blocker, greatly inhibited the increased expressions of three growth factors, VEGF, bFGF and TGF- $\beta_{1}$, and the VEGF receptor KDR in OLETF rats without affecting the plasma glucose and insulin concentrations. In OLETF rats treated with benidipine, the protein and gene expressions for these molecules were reduced nearly to those seen in control non-diabetic LETO rats. Simultaneously, benidipine treatment significantly prevented cardiac structural remodelling in OLETF rats. The increase in coronary capillary density and its secondary change, decreased oxygen diffusion distance, regressed to the control values after treatment of OLETF rats with benidipine. The decreased proportion of venular capillaries was significantly inhibited 
A
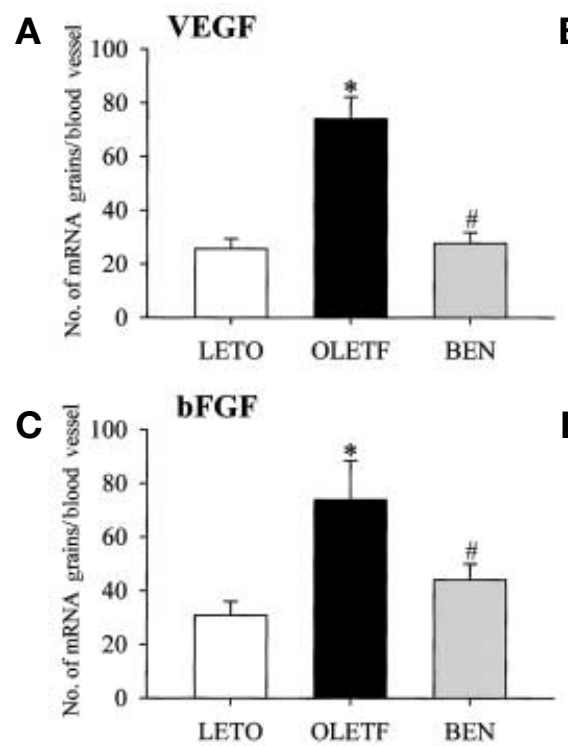

Fig. 6 (A-D). Quantitation of vascular VEGF (A), KDR (B), bFGF (C) and TGF- $\beta_{1}$ (D) mRNAs in the LV-cross sections from LETO, OLETF and benidipine-treatment OLETF (BEN) rats analysed by the in situ hybridization method. The numbers of mRNA grains for each coronary vessel are shown. For this quantitation, coronary vessels having the same size (inner diameter: $\sim 50 \mu \mathrm{m}$ ) were selected. Data are shown as the means $\pm \mathrm{SD}(20$ fields $\times 12$ samples $) .{ }^{*} p<0.01$ vs LETO; ${ }^{\#} p<0.01$ vs OLETF

by benidipine treatment. However, the ratio of venular to total capillaries did not completely return to the control values and remained modestly low despite the complete normalization of the total number of capillaries. It could be possible that transition from venular to intermediate or arteriolar capillaries mediated by mechanisms other than the angiogenic growth factor pathway occurs in the hearts from OLETF rats. Although the effect of benidipine treat-

Fig. 7 (A-C). Immunohistochemical findings for eNOS protein in the LV cross-sections from LETO (A), OLETF (B) and benidipine-treatment OLETF $(\mathbf{C})$ rats. Positive staining was found in the intimal surface of coronary vessels. Magnification $\times 400$
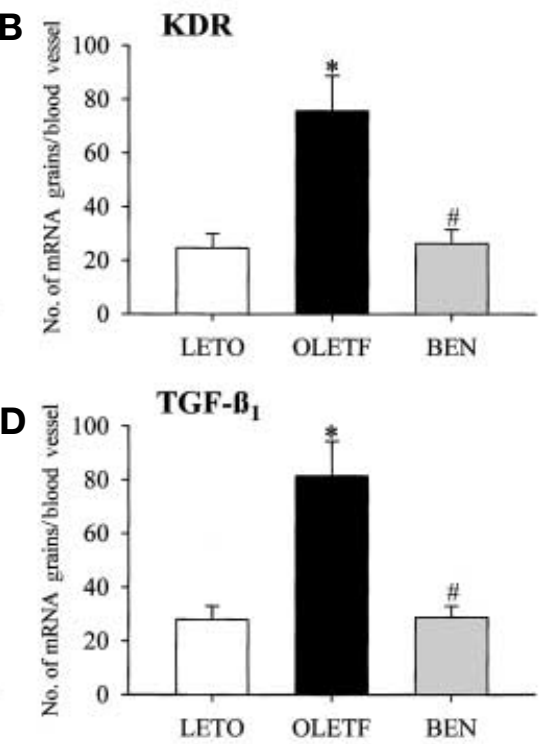

ment on the development of LV weight in OLETF rats did not reach statistical significance, cardiomyocyte size was reduced $(p<0.01)$ by benidipine treatment, indicating that calcium channel blocker therapy has an antitrophic effect at the cellular level in the diabetic rat heart. It was also found that prominent cardiac perivascular fibrosis and interstitial collagen deposition were completely improved when benidipine was given to OLETF rats. Taken together, these results suggest that benidipine prevented cardiac remodelling in diabetes by suppressing overexpression of angiogenic growth factors and the VEGF receptor.

Our additional experiments showed that treatment with hydralazine $(3 \mathrm{mg} \cdot \mathrm{kg} \cdot$ day $)$, which lowered the blood pressure to the same extent as benidipine, had no effect on the altered coronary capillary network and cardiac pervascular fibrosis in OLETF rats (unpublished observation). Furthermore, the increases in protein and gene expressions of angiogenic growth factors seen in the OLETF rat heart did not change with this treatment. It is thus not likely that the beneficial effect of benidipine in diabetic rat heart is due to its ability to lower the blood pressure.

Accumulating evidence suggests that an increase of the basal cytosolic calcium concentrations are observed in a variety of cells in diabetes and this de-
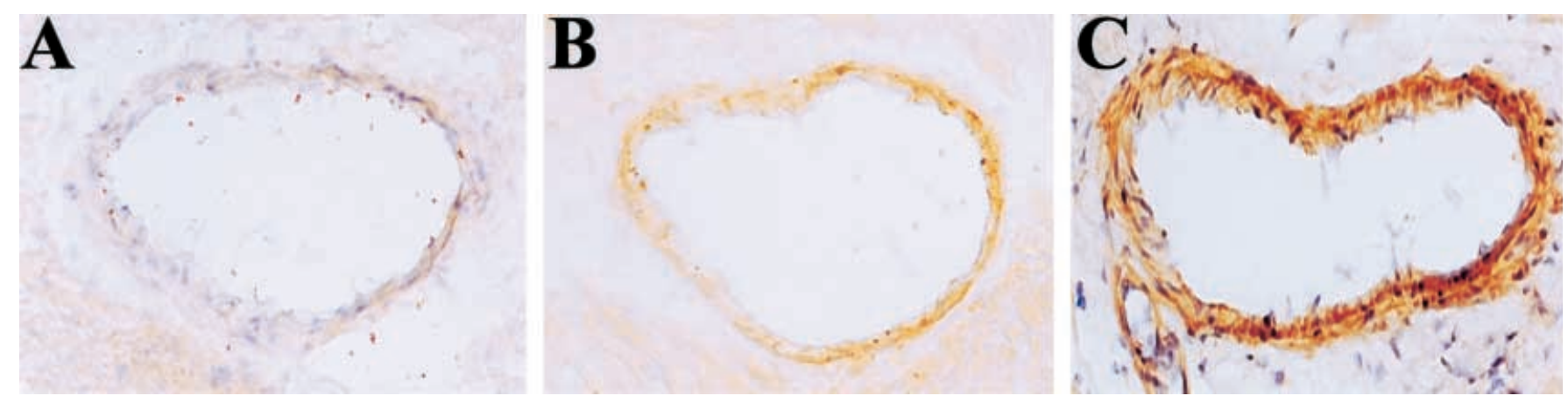

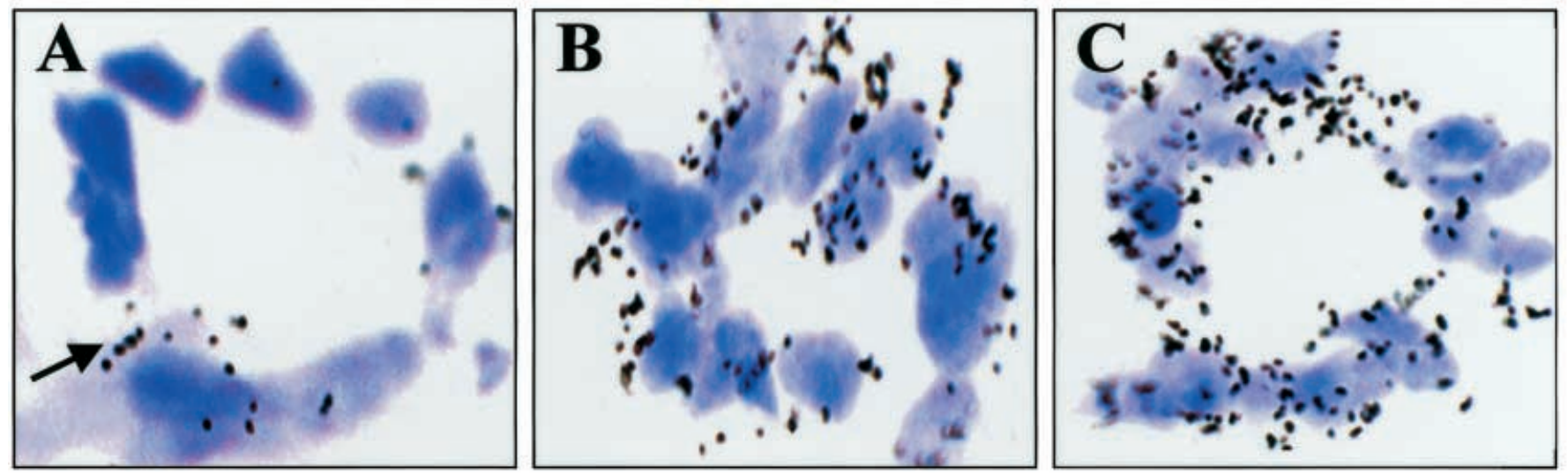

Fig. 8 (A-C). In situ hybridization analysis showing gene expression for eNOS in the LV cross-sections from LETO (A), OLETF (B) and benidipine-treatment OLETF (C) rats. Nuclei of coronary endothelial cells were stained with haematoxylin as bluish-violet. The presence of mRNA is shown by black grains (arrow) in the field. Note that eNOS mRNA is localized in the intimal surface of coronary vessels. Magnification $\times 400$

rangement is incriminated in the genesis of diabetic complications [45]. Thus, it is possible that treatment of diabetic animals with a calcium channel blocker could prevent or reverse the abnormality of the basal cytosolic calcium concentrations or both. Calcium signalling pathways have been implicated in the regulation of several cellular processes, including angiogenesis [46]. There are some reports indicating a critical role for cytosolic calcium in the induction of gene expressions for angiogenic growth factors [47-49]. Therefore, normalization of cytosolic calcium concentrations in diabetes could be followed by inhibi-

Fig.9. Immunofluorescent findings for Bcl-2 (A) and Bax (B) proteins in the LV cross-sections from LETO (left panels), OLETF (middle panels) and benidipine-treatment OLETF (BEN) (right panels) rats. Positive staining (red) was largely in coronary vessels. Magnification $\times 400$ tion of angiogenic growth factor productions despite hyperglycaemia. This could partly explain possible mechanisms for the suppressive effect of benidipine treatment on expressions of angiogenic growth factors in OLETF rats.

VEGF and bFGF not only stimulate angiogenesis but simultaneously block potently endothelial cell apoptosis execution [30]. VEGF activates the phosphatidylinositol 3'-kinase and Akt pathway and activation of Akt seems to stimulate the expression of Bcl-2, an anti-apoptotic protein, and the phosphorylation of Bad, a pro-apoptotic protein, thereby inhibiting apoptosis execution [30]. Specifically, the occurrence of endothelial cell apoptosis has deleterious effects on the development of collateral vessels, but a physiological role for endothelial cell apoptosis leading to vessel regression has been suggested $[30,50]$. In this study, in coronary vessels from OLETF rats, $\mathrm{Bcl}-2$ protein and $\mathrm{mRNA}$ were upregulated, whereas Bax protein and mRNA were downregulated, resulting in a decrease in apoptotic endothelial cells. In accordance with these observations, OLETF rats were found to have increased expression of pBad and decreased expression of active caspase-3. While pBad is the inactive, phosphorylated form of Bad that promotes its sequestration from the apoptosis regulatory machinery and thereby plays a permissive role in promoting the anti-apoptotic effect of $\mathrm{Bcl}$ proteins [51, $52]$, active caspase- 3 is important in the induction of

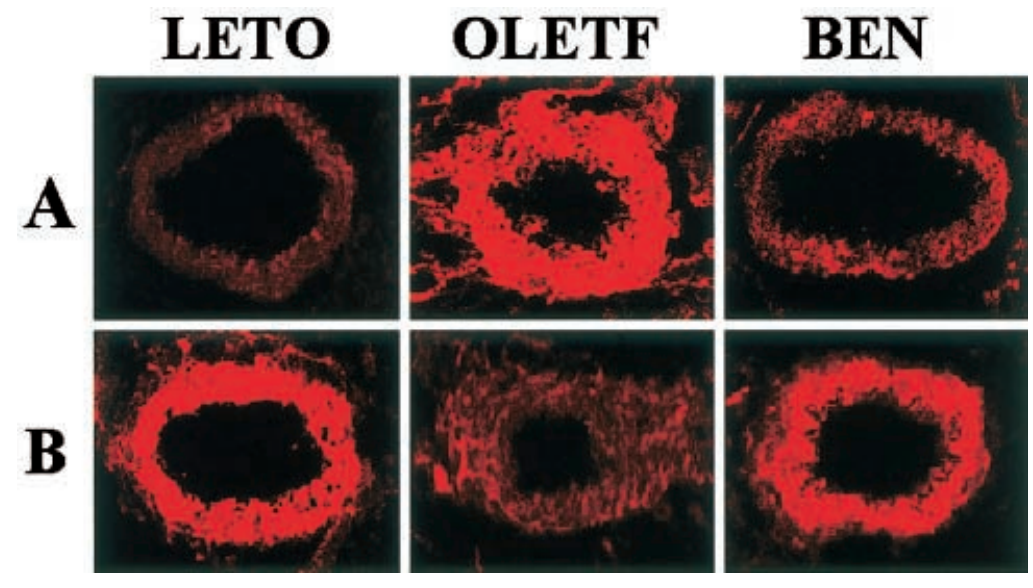


LETO
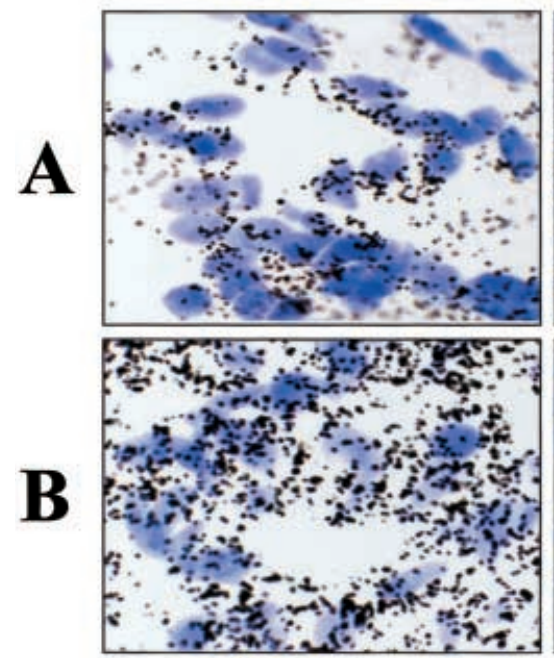

OLETF
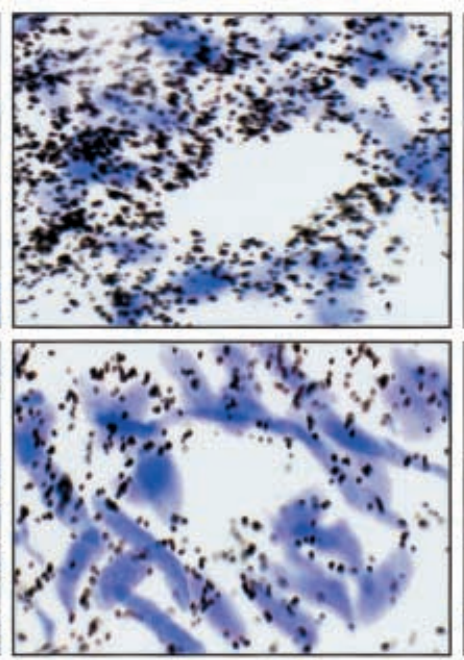

BEN
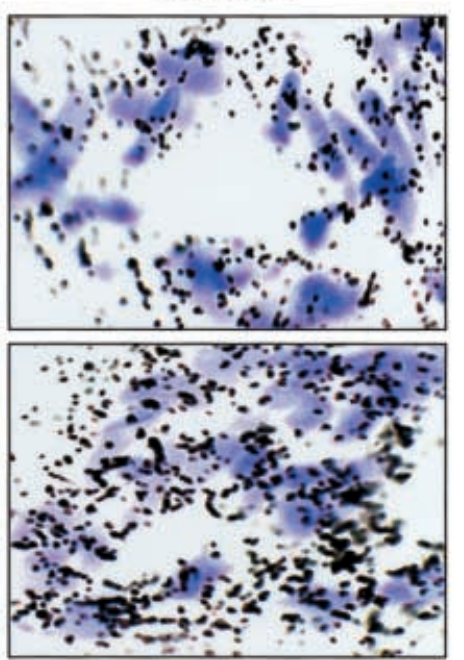

Fig. 10 (A, B). In situ hybridization analysis showing gene expressions for Bcl-2 (A) and $\mathrm{Bax}(\mathbf{B})$ in the LV cross-sections from LETO (left panels), OLETF (middle panels) and benidipine-treatment OLETF (BEN) (right panels) rats. Nuclei in coronary vessels were stained with haematoxylin as bluish-violet. The presence of mRNA is shown by black grains in the field. Note that both Bcl-2 and Bax mRNAs are mainly found in coronary vessels. Magnification $\times 400$

apoptosis by virtue of its ability to cleave structural and nuclear proteins $[53,54]$. Such changes would stem from high expressions of VEGF, bFGF and KDR in OLETF rats. We also found that eNOS expression was significantly increased in endothelial cells of coronary vessels from OLETF rats at both protein and mRNA levels. This might be associated

Fig. 11 (A, B). Immunofluorescent findings for active caspase3 (A) and pBad (B) in the LV cross-sections from LETO (left panels), OLETF (middle panels) and benidipine-treatment OLETF (BEN) (right panels) rats. Positive staining (red for active caspase-3 and green for pBad) was largely in coronary vessels. Magnification $\times 400$ with activation of Akt with VEGF [30]. Overexpression of eNOS could lead to enhanced synthesis of NO, which promotes endothelial cell survival by inhibiting the cysteine protease activity of caspases via S-nitrosylation of the reactive cysteine residue [55]. Treatment of OLETF rats with benidipine reversed the expression of $\mathrm{Bcl}-2, \mathrm{Bax}$, active caspase- 3 and $\mathrm{pBad}$, and increased the occurrence of endothelial cell apoptosis to a similar extent to that in LETO rats. These effects of benidipine probably occur through the control of the increased expressions of VEGF, bFGF and KDR in diabetic rats. Nevertheless, eNOS expression was further increased after treatment with benidipine. However, this is no surprise. Calcium channel blockers including benidipine are known to upregulate eNOS expression [56-58]. Thus, it seems likely that benidipine-induced increase in eNOS expression greatly overrode the decrease in its expression resulting from inhibition by benidipine of VEGF and KDR overexpression.

In contrast to our findings, a recent clinical study has shown increases in apoptosis of cardiomyocytes, endothelial cells and fibroblasts in specimens of myocardial tissues from diabetic patients [59]. This apparent discrepancy could be related to the diabetic state in clinical or experimental conditions. In our experi-

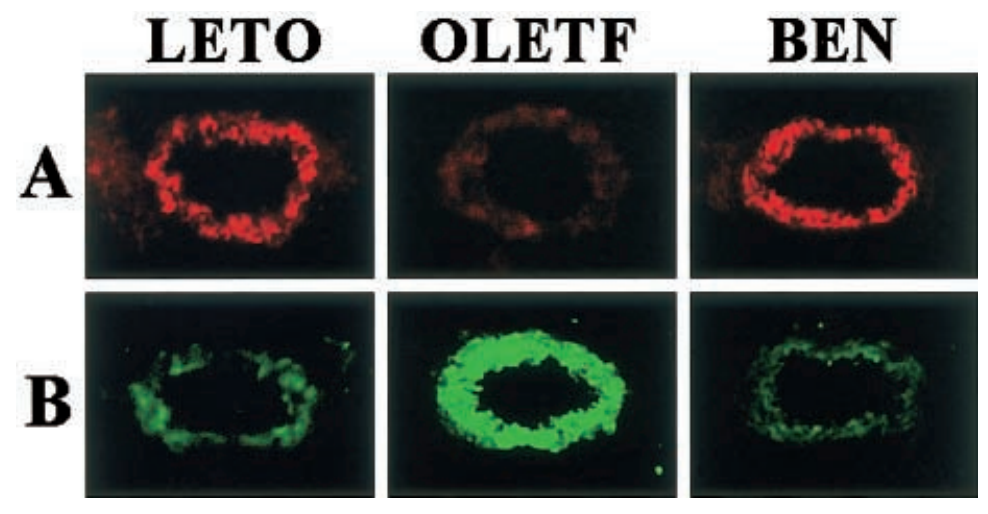



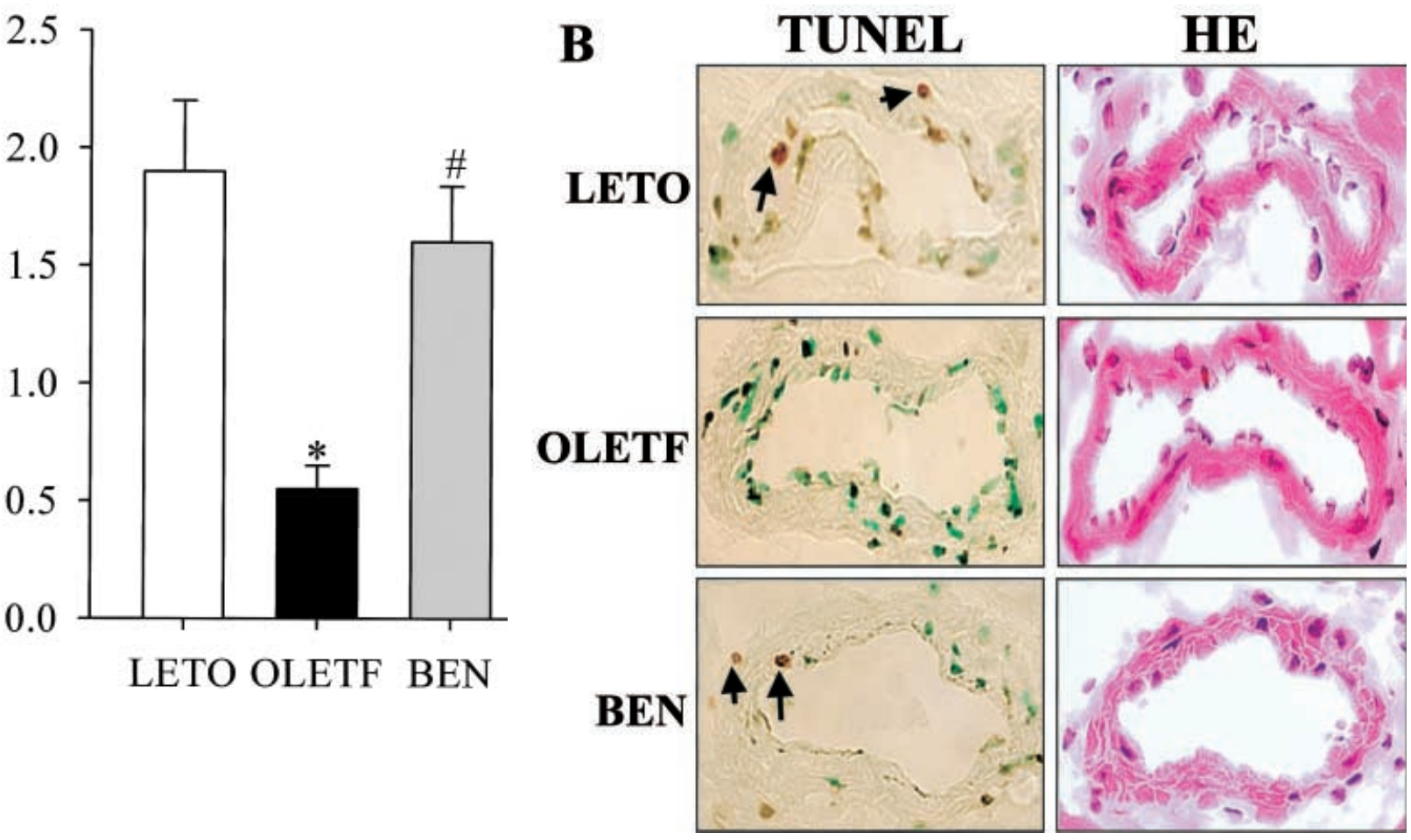

Fig. 12 (A, B). Estimation of apoptotic cells by an in situ TUNEL assay. A Apoptotic endothelial cells are expressed as a percentage of total number of endothelial cells in randomly selected coronary vessels (inner diameter: $\sim 50 \mu \mathrm{m}$ ) of the LV cross-sections from LETO, OLETF and benidipine-treatment OLETF (BEN) rats. Data are shown as the means \pm SD (40 fields $\times 12$ samples). ${ }^{*} p<0.01$ vs LETO; ${ }^{\#} p<0.01$ vs OLETF. B Left panels show the section of each group assayed for DNA fragmentation by TUNEL. Arrows indicate TUNELpositive apoptotic cells. Right panels show haematoxylin and eosin (HE) stained sections adjacent to those in left panels. Magnification $\times 400$

ments, OLETF rats were used at 20 weeks of age, which were in the stage of Type II diabetes with modest hyperglycaemia and prominent insulin resistance $[20,29,36]$. At the late stage ( $\geq 40$ weeks of age), this strain represents the conversion of diabetes from non-insulin-dependent to insulin-dependent with prominent hyperglycaemia [20,29]. We cannot rule out the possibility that pathological apoptosis of coronary endothelial cells could be promoted in association with hyperglycaemia-induced oxidative stress with disease progression of this strain.

We showed that the calcium channel blocker, benidipine, prevented diabetes-induced cardiac remodelling by inhibiting overexpression of angiogenic growth factors (VEGF, bFGF and TGF- $\beta_{1}$ ) and the VEGF receptor KDR. Our results also suggest that suppression by benidipine of expressions of VEGF, bFGF and KDR would revive physiological apoptosis, which could contribute to coronary vessel regression. Thus, early therapy with calcium channel block- ers could prove useful in preventing cardiac remodelling and in reducing the genesis of cardiac disease in diabetes.

Acknowledgements. This work was supported in part by Grantin-Aid for Scientific Research from the Ministry of Education, Science, Sports and Culture of Japan, and by Health Sciences Research Grants for Comprehensive Research on Aging and Health from the Ministry of Health, Welfare and Labour of Japan. S. Jesmin received a fellowship from the Ministry of Education, Science, Sports and Culture of Japan. We thank Prof. T. Iwanaga, Dr. C. Mowa, Mr. H. Nakamura and Ms. H. Yanase for their valuable suggestions and technical co-operation.

\section{References}

1. Garcia MJ, McNamara PM, Gordon T, Kannell WB (1974) Morbidity and mortality in diabetics in the Framingham population: sixteen year follow-up study. Diabetes 23: 105-111

2. Jarrett RJ (1989) Cardiovascular disease and hypertension in diabetes mellitus. Diabetes Metab Rev 5: 547-558

3. Shapiro LM (1985) Diabetes-induced heart-muscle disease and left ventricular dysfunction. Practical Cardiol 11: 79-91

4. Friedman JJ (1989) Vascular sensitivity and reactivity to norepinephrine in diabetes mellitus. Am J Physiol 256: 1134-1138

5. Hulper B, Wilms B (1980) Investigations of autonomic diabetic neuropathy of the cardiovascular system. In: Gries FA, Freund F, Rabe F, Berger H (eds) Aspects of autonomic neuropathy in diabetes. George Thieme Verlag, Stuttgart, pp 77-80

6. Regan TJ, Lyons MM, Ahmed SS (1977) Evidence for cardiomyopathy in familial diabetes mellitus. J Clin Invest 60 : 885-889

7. Pierce GN, Russell JC (1997) Regulation of intracellular $\mathrm{Ca}^{2+}$ in the heart during diabetes. Cardiovasc Res 34: 41-47 
8. Schrier RW, Estacio RO, Jeffers B (1996) Appropriate Blood Pressure Control in NIDDM (ABCD) Trial. Diabetologia 39: 1646-1654

9. Tuomilehto J, Rastenyte D, Birkenhäger WH et al. (1999) Effects of calcium-channel blockade in older patients with diabetes and systolic hypertension. Systolic Hypertension in Europe Trial Investigators. N Engl J Med 340: 677-684

10. Aiello LP, Avery RL, Arrigg PG et al. (1994) Vascular endothelial growth factor in ocular fluid of patients with diabetic retinopathy and other retinal disorders. $\mathrm{N}$ Engl $\mathrm{J}$ Med 331: 1480-1487

11. Quinn TP, Peters KG, De Vries C, Ferrara N, Williams LT (1993) Fetal liver kinase 1 is a receptor for vascular endothelial growth factor and is selectively expressed in vascular endothelium. Proc Natl Acad Sci USA 90: 7533-7537

12. Waltbenberger J, Claesson-Welsh L, Siegbahn A, Shibuya M, Heldin CH (1994) Different signal transduction properties of KDR and Flt-1, two receptors for vascular endothelial growth factor. J Biol Chem 269: 269888-269898

13. Pierce EA, Avery RL, Foley ED, Aiello LP, Smith LEH (1995) Vascular endothelial growth factor/vascular permeability factor expression in a mouth of retinal neovascularization. Proc Natl Acad Sci USA 92: 905-909

14. Moravski CJ, Kelly DJ, Cooper ME et al. (2000) Retinal neovascularization is prevented by blockade of the reninangiotensin system. Hypertension 36: 1099-1104

15. Tsuchida K, Makita Z, Yamagishi S et al. (1999) Suppression of transforming growth factor beta and vascular endothelial growth factor in diabetic nephropathy in rats by a novel advanced glycation end product inhibitor, OPB9195. Diabetologia 42: 579-588

16. Hovind P, Taronow L, Oestergaard PB, Parving HH (2000) Elevated vascular endothelial growth factor in type 1 diabetic patients with diabetic nephropathy. Kidney Int [Suppl] 57: S56-S61

17. Brogi E, Wu T, Namiki A, Isner JM (1994) Indirect angiogenic cytokines upregulate VEGF and bFGF gene expression in vascular smooth muscle cells, whereas hypoxia upregulates VEGF expression only. Circulation 92: 11-14

18. Butt RP, Laurent GJ, Bishop JE (1995) Collagen production and replication by cardiac fibroblasts is enhanced in response to diverse classes of growth factors. Eur J Cell Biol 68: 330-335

19. Sigel AV, Centrella M, Eghbali-Webb M (1996) Regulation of proliferative response of cardiac fibroblasts by transforming growth factor- $\beta_{1}$. J Mol Cell Cardiol 28: 1921-1929

20. Yagi K, Kim S, Wanibuchi H, Yamashita T, Yamamura Y, Iwao H (1997) Characteristics of diabetes, blood pressure, and cardiac and renal complications in Otsuka Long-Evans Tokushima Fatty rats. Hypertension 29: 728-735

21. Zimering MB, Eng J (1996) Increased basic fibroblast growth factor-like substance in plasma from a subset of middle-aged or elderly male diabetic patients with microalbuminuria or proteinuria. J Clin Endocrinol Metab 81: 4446-4452

22. Cohn JN, Ferrari R, Sharpe N (2000) Cardiac remodelling - concepts and clinical implications: A consensu s paper from an international forum on cardiac remodelling. J Am Coll Cardiol 35: 569-582

23. Danielsen R, Nordehaug JE, Lien E, Vik-Mo H (1987) Subclinical left ventricular abnormalities in young subjects with diabetes mellitus detected by digitized M-mode echocardiography. Am J Cardiol 60: 143-146

24. Galderisi M, Anderson KM, Wilson PWF, Levy D (1991) Echocardiographic evidence for the existence of a distinct diabetic cardiomyopathy: the Framingham Heart Study. Am J Cardiol 68: 85-89
25. Devereux RB, Roman MJ, Paranicas M et al. (2000) Impact of diabetes on cardiac structure and function. The Strong Heart Study. Circulation 101: 2271-2276

26. Yamazaki T, Komuro I, Zou Y et al. (1998) Efficient inhibition of the development of cardiac remodelling by a longacting calcium antagonist amlodipine. Hypertension 31: $32-38$

27. Shimada T, Yoshimiya M, Takeuchi K et al. (1998) Long acting calcium antagonist amlodipine prevents left ventricular remodelling after myocardial infarction in rats. Cardiovasc Res 37: 618-626

28. Watanabe M, Kawaguchi H, Onozuka H et al. (1998) Chronic effects of enalapril and amlodipine on cardiac remodelling in cardiomyopathic hamster hearts. J Cardiovasc Pharmacol 32: 248-258

29. Kawano K, Hirashima T, Mori S, Saitoh Y, Kurosumi M, Natori T (1992) Spontaneous long-term hyperglycemic rat with diabetic complications. Otsuka Long-Evans Tokushima Fatty (OLETF) strain. Diabetes 41: 1422-1428

30. Dimmeler S, Zeiher AM (2000) Endothelial cell apoptosis in angiogenesis and vessel regression. Circ Res 87: 434-439

31. Batra S, Rakusan K (1992) Capillary network geometry during postnatal growth in rat heart. Am J Physiol 262: H635-H640

32. Xie Z, Gao M, Koyama T (1997) The capillary of left ventricular tissue of rats subjected to coronary artery occlusion. Cardiovasc Res 33: 671-676

33. Batra S, Koyama T, Gao M, Horimoto M, Rakusan K (1992) Microvascular geometry of the rat heart. Arteriolar and venular capillary regions. Jpn Heart J 33: 817-828

34. López-de León A, Rojkind M (1985) A simple micromethod for collagen and total protein determination in formalin-fixed paraffin-embedded sections. J Histochem Cytochem 33: 737-743

35. Mowa CN, Iwanaga T (2000) Differential distribution of oestrogen receptor-alpha and -beta mRNAs in the female reproductive organ of rats as revealed by in situ hybridization. J Endocrinol 165: 59-66

36. Fukuzawa Y, Watanabe Y, Inaguma D, Hotta N (1996) Evaluation of glomerular lesion and abnormal urinary findings in OLETF rats resulting from a long-term diabetic state. J Lab Clin Med 128: 568-578

37. Batra S, Rakusan K (1992) Capillary network geometry during postnatal growth in rat hearts. Am J Physiol 262: H635-H640

38. Okada H, Fujii S, Sobel BE et al. (1999) Insulin and proinsulin regulate type- 1 plasminogen activator inhibitor and type- 1 collagen expression in rat cardiac microvascular endothelial cells: Potential role in development of coronary microvasculopathy. Pathogenesis 1: 179-188

39. Garner A (1993) Histopathology of diabetic retinopathy in man. Eye 7: 250-253

40. Benhamou PY, Carpentier P, Halimi S, Bartrand C, Mouillon M, Franco A (1990) Erythrocyte aggregation in vivo and diabetic microangiopathy. Physiologic determinants and clinical correlations. Diabetes Metab 16: 192-198

41. Ferrara N, Houck K, Jakeman L, Leung DW (1992) Molecular and biological properties of the vascular endothelial growth factor family of proteins. Endocr Rev 13: 18-32

42. Schaub MC, Hefti MA, Harder BA, Eppenberger HM (1997) Various hypertrophic stimuli induce distinct phenotypes in cardiomyocytes. J Mol Med 75: 901-920

43. Butt RP, Laurent GJ, Bishop JE (1995) Collagen production and replication by cardiac fibroblasts is enhanced in response to diverse classes of growth factors. Eur J Cell Biol 68: 330-335 
44. Agocha A, Lee H-W, Eghbali-Webb M (1997) Hypoxia regulates basal and induced DNA synthesis and collagen type 1 production in human cardiac fibroblasts: Effects of transforming growth factor- $\beta_{1}$, thyroid hormone, angiotensin II and basic fibroblast growth factor. J Mol Cell Cardiol 29: 2233-2244

45. Levy J, Gavin JR $3^{\text {rd }}$, Sowers JR (1994) Diabetes mellitus: a disease of abnormal cellular calcium metabolism. Am J Med 96: 260-273

46. Kohn EC, Alessandro R, Spoonster J, Wersto RP, Liotta LA (1995) Angiogenesis: Role of calcium-mediated signal transduction. Proc Natl Acad Sci USA 92: 1307-1311

47. Levy AP, Levy NS, Loscalzo J et al. (1995) Regulation of vascular endothelial growth factor in cardiac myocytes. Circ Res 76: 758-766

48. Hoper MM, Voelkel NF, Bates TO et al. (1997) Prostaglandins induce vascular endothelial growth factor in a human monocytic cell line and rat lung via cAMP. Am J Respir Cell Mol Biol 17: 748-756

49. Ruiz-Ortega M, Egido J (1997) Angiotensin II modulates cell growth-related events and synthesis of matrix proteins in renal interstitial fibroblasts. Kidney Int 52: 1497-1510

50. Langille BL, Bendeck MP, Keeley FW (1989) Adaptations of carotid arteries of young and mature rabbits to reduced carotid blood flow. Am J Physiol 256: H931-H939

51. Zha J, Harada H, Yang E, Jockel J, Korsmeyer SJ (1996) Serine phosphorylation of death agonist BAD in response to survival factor results in binding 14-3-3 not Bcl-XL. Cell 87: 619-628
52. Zha J, Harada H, Osipov K et al. (1997) BH3 domain of $\mathrm{BAD}$ is required for heterodimerization with $\mathrm{Bcl}-\mathrm{XL}$ and pro-apoptotic activity. J Biol Chem 272: 24101-24104

53. Janicke RU, Sprengart ML, Wati MR, Porter AG (1998) Caspase-3 is required for DNA fragmentation and morphological changes associated with apoptosis. J Biol Chem 273: 9357-9360

54. Hampton MB, Fadeel B, Orrenius S (1998) Redox regulation of the caspase during apoptosis. Ann NY Acad Sci 854: 328-335

55. Dimmeler S, Haendeler J, Nehls M, Zeiher AM (1997) Suppression of apoptosis by nitric oxide via inhibition of ICE-like and CPP32-like proteases. J Exp Med 185: 601-608

56. Kobayashi N, Yanaka H, Tojo A, Kobayashi K, Matsuoka H (1999) Effects of amlodipine on nitric oxide synthase mRNA expression and coronary microcirculation in prolonged nitric oxide blockade-induced hypertensive rats. J Cardiovasc Pharmacol 34: 173-181

57. Ding Y, Vaziri ND (2000) Nifedipine and diltiazem but not verapamil up-regulate endothelial nitric synthase expression. J Pharmacol Exp Ther 292: 606-609

58. Yamashita T, Kawashima S, Ozaki M et al. (2001) A calcium channel blocker, benidipine, inhibits intimal thickening in the carotid artery of mice by increasing nitric oxide production. J Hypertens 19: 451-458

59. Frustaci A, Kajstura J, Chimenti C et al. (2000) Myocardial cell death in human diabetes. Circ Res 87: 1123-1132 